\title{
The earliest evidence of true lambdoid craniosynostosis: the case of "Benjamina", a Homo heidelbergensis child
}

\author{
Ana Gracia • Juan F. Martínez-Lage • \\ Juan-Luis Arsuaga • Ignacio Martínez • \\ Carlos Lorenzo • Miguel-Ángel Pérez-Espejo
}

Published online: 2 April 2010

(C) Springer-Verlag 2010

\begin{abstract}
Background The authors report the morphological and neuroimaging findings of an immature human fossil (Cranium 14) diagnosed with left lambdoid synostosis.

Discussion The skull was recovered at the Sima de los Huesos site in Atapuerca (Burgos, Spain). Since the human fossil remains from this site have been dated to a minimum age of 530,000 years, this skull represents the earliest evidence of craniosynostosis occurring in a hominid. A brief historical review of craniosynostosis and cranial deformation is provided.
\end{abstract}

\footnotetext{
A. Gracia $\cdot$ J.-L. Arsuaga $\cdot$ I. Martínez

Centro Mixto UCM-ISCIII de Evolución y Comportamiento

Humanos,

C. Sinesio Delgado 4, Pabellón14,

28029 Madrid, Spain

A. Gracia

J. F. Martínez-Lage $(\bowtie) \cdot$ M.-Á. Pérez-Espejo

Regional Service of Neurosurgery,

Virgen de la Arrixaca University Hospital,

30120, El Palmar,

Murcia, Spain

e-mail: juanf.martinezlage@cablemurcia.com

\section{Martínez}

Área de Paleontología, Departamento de Geología,

Universidad de Alcalá de Henares,

28871 Alcalá de Henares,

Madrid, Spain

C. Lorenzo

Institut de Paleoecologia Humana i Evolució Social (IPHES),

Area de Prehistoria, Facultat de Lletres,

Universitat Rovira i Virgili,

Plaça Imperial Tàrraco, 1 ,

43005 Tarragona, Spain
}

Keywords Craniosynostosis · Lambdoid synostosis · Paleopathology · Deformational plagiocephaly $\cdot$ Posterior plagiocephaly $\cdot$ Skull deformation $\cdot$ Human evolution

\section{Introduction}

The term craniosynostosis refers to the premature closure of one or several cranial sutures. The condition can be primary, which encompasses genetic causes, or secondary when there exists an underlying disorder responsible for the premature fusion $[16,17,28]$. Early closure of the cranial sutures can produce aesthetic deformity of the head and damage of intracranial structures, as neurological lesions of varying-degree, visual impairment and/or raised intracranial pressure $[16,28,29]$. The prevalence of craniosynostosis has been estimated in 5-10/10,000 live births [16, 17, 36]. The premature fusion of the sutures, either isolated or in combination, gives rise to diverse skull shapes, receiving each one a different name (plagiocephaly, scaphocephaly, brachycephaly, trigonocephaly, etc.) $[16,17,20,21]$.

Posterior plagiocephaly refers to an asymmetric shape of the posterior part of the cranium that can be due either to true parieto-occipital bone fusion or to a deformed occiput by external forces $[14,19,22,25,30,31,36,38]$. The distinction between these two conditions has proven to be quite difficult and some authors include a "sticky" lambdoid suture within the group of lambdoid synostosis $[22,25,31]$. The proportion of true lambdoid craniosynostosis ranges from 1 to $3 \%$ of all craniosynostoses. Much more frequent is the so-called deformational or positional posterior plagiocephaly, which has been related with the sleeping supine position recommended by the American Academy of Pediatrics to prevent the sudden infant death syndrome $[19,22,30,36]$. In fact, the prevalence of 
posterior plagiocephaly without synostosis has increased in recent years and is estimated in 33:10,000 [22, 30, 36]. This differentiation is important, as deformational plagiocephaly rarely requires surgical treatment while true lambdoid synostosis does. The diagnosis of lambdoid synostosis usually entails performing a computerized tomography (CT) head scan with 3-D reconstructions, and its exact nature can be confirmed by the histopathological study of the excised suture $[14,20,21,25,31]$.

\section{Craniosynostosis throughout the history}

Works by Hippocrates, Galen, and Celsus alluded to abnormal cranial shapes. Sommering and Hyrtl described premature skull synostosis during the 19th century, but it was not until Virchow, in 1851, that craniosynostosis was more precisely categorized. Surgical treatment of the condition was initiated by Lannelongue in 1890 and Lane in 1892 [24]. During the 1970s and 1980s, surgical and anesthetic techniques improved considerably, leading to the widespread utilization of surgical correction of the craniosynostoses. Subsequently, new anesthetic and surgical techniques greatly reduced procedural morbidity and mortality adding, at the same time, better aesthetic results that have become excellent in most cases [24].

Apart from the previously mentioned historical physicians, craniosynostosis has been recognized in detail in several works of paleopathology. Prokopec et al.'s research on human remains of Australian aborigines $(8,000-$ 7,000 years BC) includes the description of a 5-year-old child with generalized craniosynostosis and pitting of the occipital bones attributed to anemia [34]. Kutterer and Alt have provided a study of 76 skulls from the prehistoric population of Münsingen-Rain in Switzerland that included three cases of craniosynostosis, one with scaphocephaly and complete fusion of the sagittal suture, and two with anterior plagiocephaly due to closure of the frontosphenoidal suture [26]. Seven additional skulls showed diverse craniofacial asymmetry of undetermined nature [26]. Shapiro reports briefly the nomenclature of the diverse forms of abnormal head shapes appearing in the 'Talmud' [39]. Charom signifies abnormal head shape and kilon, liftan, makovan, shakua, and shekifas refer to diverse head abnormalities depicted in the Talmud and, later on, in Rabbenu Gershom's (960-1028) and Maimonides' (11351204) medical treatises [20].

Braverman et al. have studied the physical features of Akhenaten (also known as Amenophis IV, 1,377 BC) that included gynecomasty and an abnormal skull shape, probably as a result of inbreeding [10]. These authors also summarized in a table the endocrine and cranial abnormalities (abnormally elongated occiput) documented in sculp- tures of at least 14 rulers belonging to the 18th dynasty. They assigned these abnormalities to a recently described dominantly transmitted disorder, namely the aromatase excess syndrome [10]. In addition, Boyer et al. have reported the neuroimaging findings of the skull and cervical spine belonging to Tutankhamen, the last pharaoh of the 18th dynasty, who died at a young age of, approximately, 18 years. In this work, the authors ruled out a presumed violent cause for the pharaoh's death, but they do not mention the obvious king's dolicocephalic head shape [9].

Di Rocco described the abnormal head, with reduced latero-lateral diameter and mild hypothelorism, depicted in the marble portrait of Pericles (495-429 BC) [18]. Apparently, this Greek politician suffered from sagittal synostosis that caused him no mental impairment as he was recognized as being in possession of a brilliant mind. On the contrary, Tersites, depicted as having a pointed head in Homer's Iliad, had a rather spiteful behavior perhaps related to his misshapen head.

In the Iberian Peninsula, the oldest historical evidence of craniosynostosis that we have found in the literature has been documented in a Muslim cemetery of Bab-al-Hanax, from 11th to14th centuries [35]. Out of 343 burials from different occupation levels, two cases were referred as deformed skulls. One cranium displays premature fusion of the right lambdoid suture (true plagiocephaly) and the second one presents scaphocephaly due to the fusion of the sagittal suture.

Leovic et al.'s researches on the prehistoric human skeletal remains from the collections of Arizona State University and the San Diego Museum of Man have reported both unintentional and intentional cranial deformation in prehistoric Native Americans [27]. Pospíšilová and Procházková studied 745 dry skulls (645 adults and 98 children) from Broumov Ossuary in the Czech Republic (13th-18th centuries), and found plagiocephaly in $14.2 \%$ of the specimens [26]. Deformational posterior plagiocephaly was discovered in 93 instances (12.48\%) and true lambdoid synostosis in 13 (1.74\%) cases [33]. There is also a mention to the high frequency of craniosynostosis in skulls recovered from the cemetery of St. James and St. Mary Magdalene Medieval Hospital in Chichester, England, that functioned as an almshouse since $1450 \mathrm{AD}$, where children with congenital defects were abandoned [23].

Gracia et al. have reviewed two reports of Pleistocene hominid fossils with cranial deformities [23]. The first one is the cranium of Salé, whose occipital deformation was attributed to torticollis congenita. The second one, Singa 1 skull, presents temporal bone pathology and was cited as having sagittal synostosis but, according to these authors, this specimen does not exhibit the characteristic elongated cranial shape of scaphocephaly [23]. 


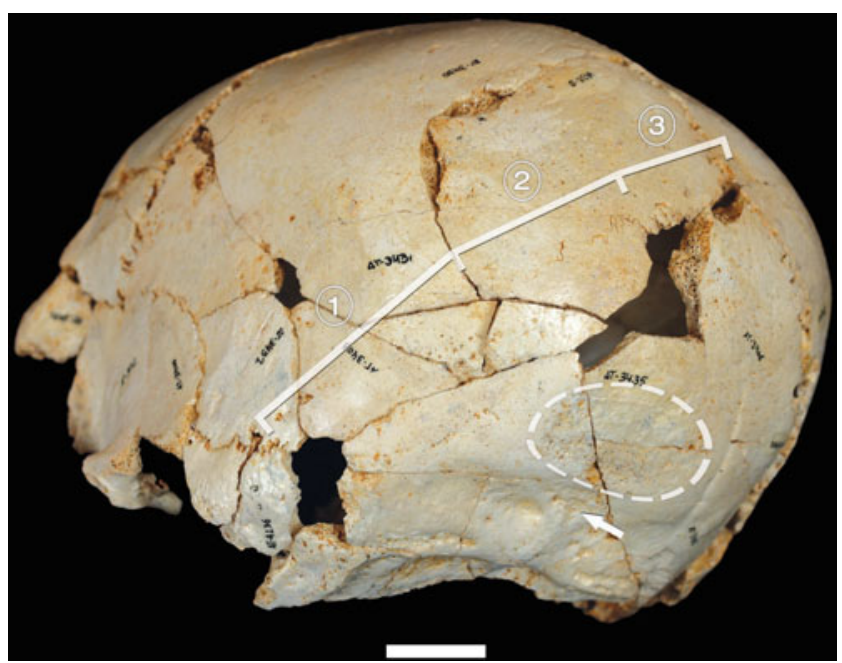

Fig. 1 Cranium 14 showing closure of part of the left lambdoid suture. 1 completely fused. 2 Fused but with external traces of the suture, 3 portion of the suture still open (see ref. [23]). The arrow points to the inion and the spaced line circumscribes the foreshadowing suprainiac region, a character state present in this population. Scale bar corresponds to $2 \mathrm{~cm}$

\section{"Benjamina": the Middle Pleistocene child with true lambdoid synostosis}

The Sierra de Atapuerca (Burgos, Spain) paleo-archeological sites were discovered at the end of the 19th century, while the mining society "the Sierra Company Limited" started the construction of a railway that cut across the cretaceous hill, exposing the karstic cavities filled up of sediments that constitute the paleo-archeological sites under excavation. Three sites have yielded human fossil remains, the oldest being the Trinchera Elefante site [13], dated in more than 1.2 My. During the 1994 field season, at the trench site called Gran Dolina, while making a survey in level TD-6, dated in more than 780,000 years, a hominin fossil was found. After two field seasons, hominin remains of at least six individuals were recovered that meant enough material to describe "the first Europeans". The Atapuerca research team defined, with the new material from Gran Dolina, a new species of the genus Homo: Homo antecessor [6-8, 11, 12].

On the other hand, at the Sima de los Huesos site, skeletal remains of at least 28 individuals are being excavated. They belong to a Middle Pleistocene population assigned to Homo heidelbergensis species that lived in Burgos more than 530,000 years ago [2-5]. More ample descriptions dealing with these archeological excavations have already been published [2-8, 11-13, 23, 32].

Recently, Gracia et al. have reported the finding of Cranium 14 belonging to the Sima de los Huesos (Atapuerca) hominin sample [23]. The cranium was recovered in many pieces during the 2001-2002 field seasons and was reconstructed in subsequent years.
Cranium 14 consists of an almost complete neurocranium, lacking the facial structures. After restoration, this skull revealed the existence of a left true lambdoid synostosis that comprises $2 / 3$ of the lateral and medial part of the suture (Figs. 1 and 2). The cranium also shows contralateral parietal bossing, ipsilateral occipitomastoid bulging and an ipsilateral downward tilt of the skull base. The right (contralateral) frontal bone also presents some bulge. It is very noticeable that the compensatory alteration on the frontal bone produced a verticalization of the forehead, giving a final shape that closely resembles the frontal region of modern humans. Interestingly, there is, at least, one small wormian bone on the right lambdoid suture, a finding that has been reported to be relatively frequent in human cases of craniosynostosis [1, 37] (Figs. 2 and 3a, b). The study of the spheno-occipital and jugular synchondroses showed that the cranium had not reached adulthood, and that the death of the hominid happened around 10 12 years of age. CT reconstruction also ascertained that the intracranial volume of Cranium 14 was approximately $1,200 \mathrm{~cm}^{3}$ [23]. In addition, the internal surface of the specimen showed marked endocranial convolutions and signs of enlarged subarachnoid spaces, which have been also documented in cases of positional plagiocephaly and of true craniosynostosis [15, 30, 38]. Regarding etiology of the synostosis, Gracia et al. mention the possibility of intrauterine trauma, fetal head constraint, or torticollis

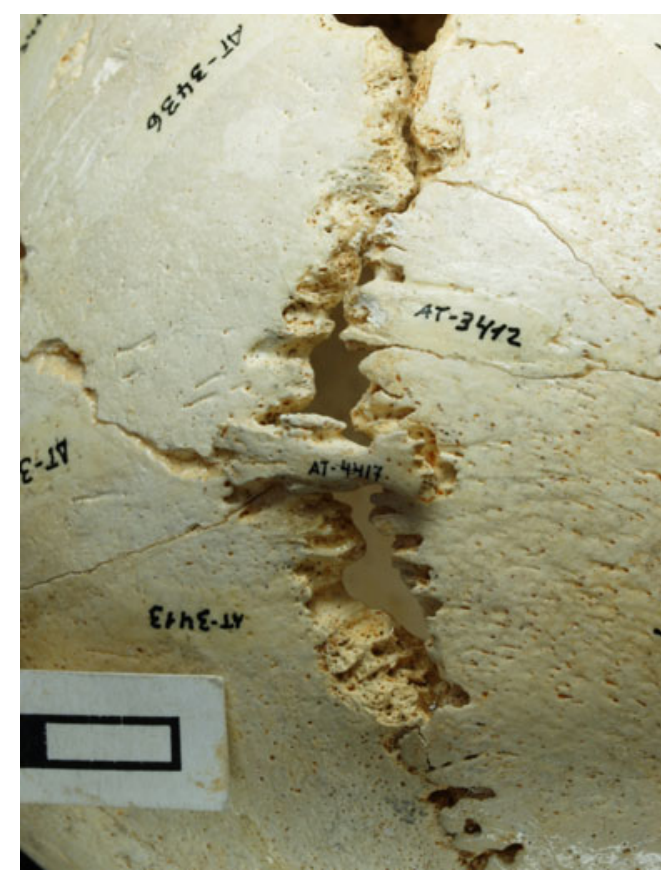

Fig. 2 Small wormian bone placed in the right lambdoid suture of Cranium 14. The space between the suture borders suggests that there was probably one more supernumerary ossicle. Scale bar corresponds to $1 \mathrm{~cm}$ 
Fig. 3 Computerized tomography $3-\mathrm{D}$ reconstruction of a wormian bones in a recent case of positional posterior plagiocephaly (arrow), b wormian bones in a 6-month-old girl with sagittal craniosynostosis (arrows), c true lambdoid synostosis in a 1-month-old child (arrow)
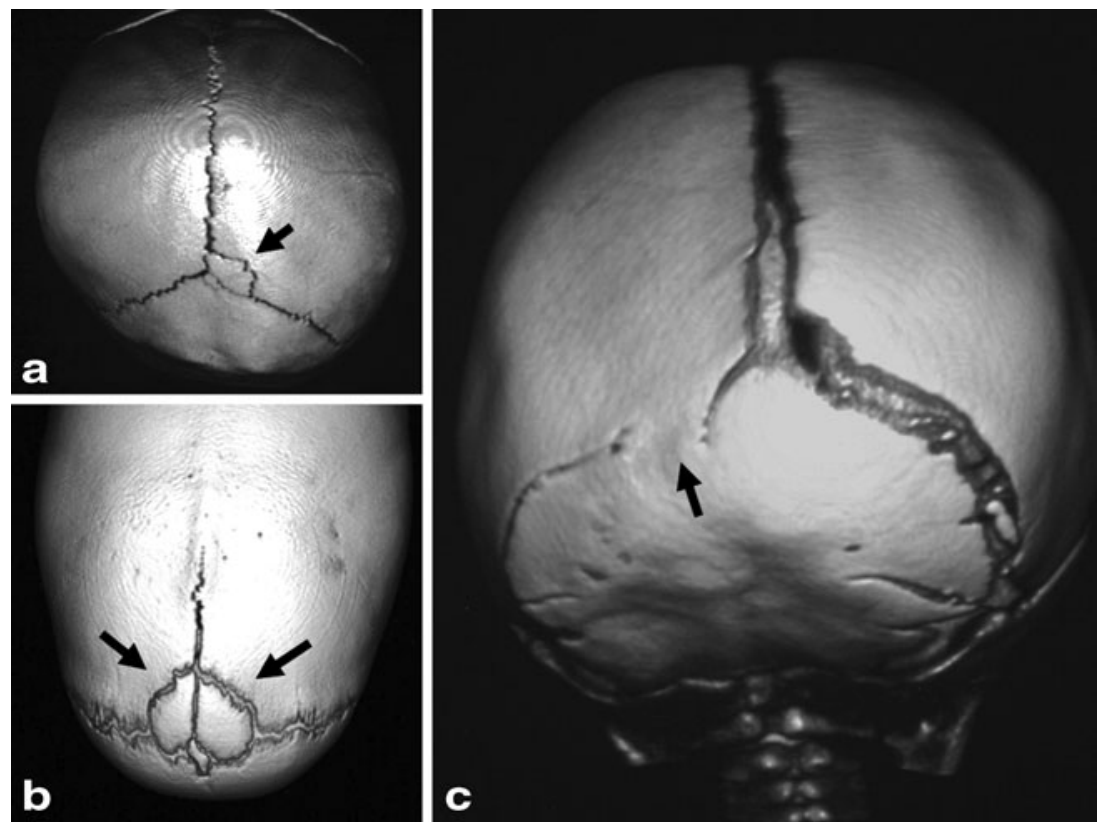

congenita. Fetal head constraint causing craniosynostosis has also been documented in the context of oligoamnios. Other etiologies, as metabolic diseases (rickets or anemia) can be ruled out due to absence of bone changes that occur in these conditions [23].

Cranium 14 has been given the nickname of "Benjamina", which is the feminine form of Benjamin, a Hebrew name to designate the 'favorite member of a family' (Fig. 4, cover picture), in many cases given to the youngest child. The fact that Benjamina reached at least the age of 10 years

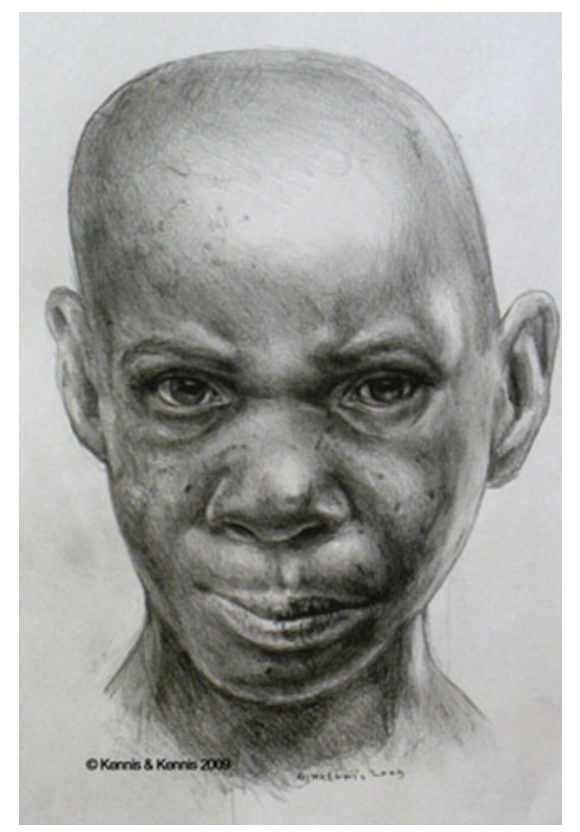

Fig. 4 Artistic recreation of Benjamina's appearance, the Middle Pleistocene girl with true left lambdoid craniosynostosis (also used as the cover picture) leads to the conclusion that the group to which she belonged, in spite of the disfiguring features that the child might have had, did not act against her as what happened with handicapped children throughout the history in different times and in many cultures [23]. On the contrary, the evidence supports social care among these very ancient hominids, ancestors of Neanderthals. Benjamina's Cranium 14 represents a most significant paleopathological discovery, and constitutes the earliest (pre-) historical evidence of craniosynostosis reported in the current literature.

Acknowledgments This study was financed by the Spanish Government through the Ministerio de Ciencia y Tecnología, Project No. CGL2006-13532-C03-02 and MICINN CGL2009-12703-C0303. The field excavation work is financed by the Junta de Castilla y León and Fundación Atapuerca. We thank the Atapuerca excavation team, especially that of the Sima de los Huesos and A. Bonmatí, F. Gracia and J. Lira, for their help with the figure and photographs (Figs. 1 and 2), and to Kennis \& Kennis for their Benjamina "portrait" (Fig. 4).

\section{References}

1. Agrawal D, Steinbok P, Cochrane DD (2006) Pseudoclosure of the anterior fontanelle by wormian bone in isolated sagittal craniosynostosis. Pediatr Neurosurg 42:135-137

2. Arsuaga JL, Martínez I, Gracia A, Carretero JM, Carbonell E (1993) Three new human skulls from the Sima de los Huesos Middle Pleistocene site in Sierra de Atapuerca, Spain. Nature 362:534-537

3. Arsuaga JL, Martínez I, Gracia A, Lorenzo C (1997) The Sima de los Huesos crania (Sierra de Atapuerca, Spain). A comparative study. J Hum Evol 33:219-281

4. Arsuaga JL, Carretero JM, Lorenzo C, Gracia A, Martínez I, Bermúdez de Castro JM, Carbonell E (1997) Size variation in Middle Pleistocene humans. Science 277:1086-1088 
5. Arsuaga JL, Lorenzo C, Carretero JM, Gracia A, Martínez I et al (1999) A complete human pelvis from the Middle Pleistocene of Spain. Nature 399:255-258

6. Arsuaga JL, Martínez I, Lorenzo C, Gracia A, Muñoz A, Alonso O, Gallego J (1999) The human cranial remains from Gran Dolina Lower Pleistocene site (Sierra de Atapuerca, Spain). J Hum Evol $37: 431-457$

7. Bermúdez de Castro JM, Arsuaga JL, Carbonell E, Rosas A, Martínez I, Mosquera M (1997) A hominid from the Lower Pleistocene of Atapuerca, Spain: possible ancestor to Neanderthals and modern humans. Science 276:1392-1395

8. Bermúdez de Castro JM, Martinón-Torres M, Carbonell E, Sarmiento S, Rosas A, van der Made J, Lozano M (2004) The Atapuerca sites and their contribution to the knowledge of human evolution in Europe. Evol Anthropol 13:25-41

9. Boyer RS, Rodin EA, Grey TC, Connolly RC (2003) The skull and cervical spine radiographs of Tutankhamen: a critical appraisal. AJNR Am J Neuroradiol 24:1142-1147

10. Braverman IM, Redford DB, Mackowiak PA (2009) Akhenaten and the strange physiques of Egypt's 18th dynasty. Ann Intern Med 150:556-560

11. Carbonell E, Bermúdez de Castro JM, Arsuaga JL, Díez JC, Rosas A, Cuenca-Bescós E et al (1995) Lower Pleistocene Hominids and Artifacts from Atapuerca-TD6 (Spain). Science 269:826-830

12. Carbonell E, Esteban M, Martín A, Nájera M, Mosquera X, Rodríguez P et al (1999) The Pleistocene site of Gran Dolina, Sierra de Atapuerca, Spain: a history of the archaeological investigations. J Hum Evol 37:313-324

13. Carbonell E, Bermúdez de Castro JM, Parés JM, Perez-González A, Cuenca-Bescós G et al (2008) The first hominin of Europe. Nature 452:465-470

14. Carmel PW, Luken MG III, Ascherl GF Jr (1981) Craniosynostosis: computed tomographic evaluation of skull base and calvarial deformities and associated intracranial changes. Neurosurgery 9:366-372

15. Chadduck WM, Chadduck JB, Boop FA (1992) The subarachnoid spaces in craniosynostosis. Neurosurgery 30:867-871

16. Cohen MM Jr (2000) Diagnosis, evaluation and management. In: Cohen MMJ, MacLean RE (eds) Craniosynostosis. Oxford University Press, New York, pp 112-118

17. Coussens AK, Wilkinson CR, Hughes IP, Morris CP, van Daal A, Anderson PJ, Powell BC (2007) Unraveling the molecular control for calvarial suture fusion in children with craniosynostosis. BMC Genomics 8:458

18. Di Rocco C (2005) Craniosynostosis in old Greece: political power and physical deformity. Child's Nerv System 21:859, cover picture

19. Di Rocco C, Scogna A, Velardi F, Zambelli HJL (1998) Posterior plagiocephaly: craniosynostosis or skull molding? Crit Rev Neurosurg 8:122-130

20. Furuya Y, Edwards MSB, Alpers CE, Tress BM, Ousterhout DK, Norman D (1984) Computerized tomography of the cranial sutures. Part 1: comparison of suture anatomy in children and adults. J Neurosurg 61:53-58

21. Furuya Y, Edwards MSB, Alpers CE, Tress BM, Ousterhout DK, Norman D (1984) Computerized tomography of the cranial sutures. Part 2: abnormalities of sutures and skull deformity in craniosynostosis. J Neurosurg 61:59-70

22. Goodrich JT, Argamaso R (1996) Lambdoid stenosis (posterior plagiocephaly) and craniofacial asymmetry: long-term outcomes. Child's Nerv Syst 12:720-726
23. Gracia A, Arsuaga JL, Martínez I, Lorenzo C, Carretero JM, Bermúdez de Castro JM, Carbonell E (2009) Craniosynostosis in the Middle Pleistocene human Cranium 14 from the Sima de los Huesos, Atapuerca, Spain. Proc Natl Acad Sci USA 106:6573-6578

24. Grant J (2001) The history of Pediatric Neurosurgery. In American Society of Pediatric Neurosurgery, Section of Pediatric Neurosurgery of the AANS (eds). Pediatric Neurosurgery: surgery of the developing nervous system. Saunders, Philadelphia, pp 14-16

25. Hinton DR, Becker LE, Muakkassa KF, Hoffman HJ (1984) Lambdoid synostosis. Part 1. The lambdoid suture: normal development and pathology of "synostosis". J Neurosurg 61:333-339

26. Kutterer A, Alt KW (2008) Cranial deformations in an iron age population from Münsingen-Rain, Switzerland. Int J Osteoarchae$\log 18: 392-406$

27. Lekovic GP, Baker B, Lekovic JM, Preul MC (2007) New World cranial deformation practices: historical implications for pathophysiology of cognitive impairment in deformational plagiocephaly. Neurosurgery 60:1137-1147

28. Martínez-Lage JF, Poza M, Lluch T (1996) Craniosynostosis in neural tube defects: a theory on its pathogenesis. Surg Neurol 46:465-469

29. Martínez-Lage JF, Alamo L, Poza M (1999) Raised intracranial pressure in minimal forms of craniosynostosis. Child's Nerv Syst $15: 11-15$

30. Martínez-Lage JF, Ruíz-Espejo AM, Gelabert A, Pérez-Espejo MA, Guillén-Navarro E (2006) Positional skull deformities in children: skull deformation without synostosis. Child's Nerv Syst 22:368-374

31. Muakkassa KF, Hoffman HJ, Hinton DR, Hendrick EB, Humphreys RP, Ash J (1984) Lambdoid synostosis. Part 2: review of cases managed at The Hospital for Sick Children 1972-1982. J Neurosurg 61:340-347

32. Perez J, Gracia A, Martínez I, Arsuaga JL (1997) Paleopathological evidence of the cranial remains from the Sima de los Huesos Middle Pleistocene site (Sierra de Atapuerca, Spain). Description and preliminary inferences. J Hum Evol 33:409421

33. Popspišilová B, Procházková O (2006) Paleopathological findings of dry skulls with plagiocephaly. Acta Med (Hradec Králové) 49:219-226

34. Prokopec M, Pretty GL, Smith P (1994) Australian aboriginals: prehistoric south. Var Evol 4:23-56

35. Roca de Togores C (2001) Aspectos paleopatológicos de los restos óseos humanos del cementerio islámico de Bab Al-Hanax (Valencia). Actas V Congreso Nacional de Paleopatología. Alcalá la Real, Jaén, 1999, pp 349-352

36. Rekate HL (1998) Occipital plagiocephaly: a critical review of the literature. J Neurosurg 89:24-30

37. Sanchez-Lara PA, Graham JM Jr, Hing AV, Lee J, Cunningham M (2007) The morphogenesis of wormian bones: a study of craniosynostosis and purposeful cranial deformation. Am J Med Genet 143A:3243-3251

38. Sawin PD, Muhonen MG, Menezes AH (1996) Quantitative analysis of cerebrospinal fluid spaces in children with occipital plagiocephaly. J Neurosurg 85:428-434

39. Shapiro R (1989) Craniosynostosis in the Talmud. Radiology $172: 230$ 